\title{
Вродени шийни образувания и аномалии
}

\author{
К. Попов, Н. Цаков, Д. Скерлева \\ СБАЛО-ЕАД, Отделение УНГ-болести, \\ Български национален раков регистьр
}

\section{Въведение}

При изследването на пациент с шийно образувание първото, което трябва да се има предвид, е към коя възрастова група спада пациентьт, което позволява бързо ориентиране какво може да е заболяването - вродено, възпалително или неопластично. Например в детска и млада възраст образуванията са предимно от възпалително естество, следвани от вродени и аномалии на растежа и развитието. Следващият важен ориентир след определянето на възрастовата група е локализацията по шията. Това е от съществено значение за вродените и аномалиите на растежа и развитието. За страничните отдели на шията характерна находка са кистите, произхождащи от хрилните дъги и ларингоцеле; образувания по срединната линия могат да представляват кисти на ductus thyroglossus, кисти на тимуса, дермоидни кисти, тератоми или ранула. Някои от тези лезии могат да обхващат цялата шия (хемангиоми и васкуларни малформации). Всяка от тези лезии ще бъде разгледана поотделно, а допълнително ще се разгледа и един рядък вид лезия, която може да се прояви като шийно образувание - дупликатура на хранопровода.

\section{Кисти на хрилните дъги}

Ембриологията на хрилния апарат, от който се образуват много структури на лицето и шията, е сложна. От нарушения в неговото развитие се образуват кисти на хрилните цепки, синуси и фистули. Развитието на хрилния апарат започва през втората ембрионална седмица. Счита се, че то приключва през шеста-седма 
ембрионална седмица. Хрилният апарат се развива латерално на предното черво и се състои от пет дъги (мезодермални). Те са изградени от външна ектодермално постлана бразда (фарингеална бразда) и вътрешна ендодермално постлана конкавна страна (фарингеален джоб). От всяка хрилна дъга, фарингеална бразда и фарингеално джобче произлизат точно определени структури $(1,2)$. Всяка хрилна дъга съдържа хрущял, мускули и нервни клончета, свързани с тях. Фарингеалните дъги се номерират от краниално към каудално, но петата дъга не се появява на повърхността на хрилния апарат и носи името шеста фарингеална дъга. При развитието на хрилния апарат, първата и втората дъга растат каудално, а едновременно с това нараства мезодермата, която формира епиперикарден гребен. Накрая от него ще се развият m. sternocleidomastoideus, m. trapezius, инфрахиодната и лингвална мускулатура. Развитието на мезодермата спира развитието на трета и четвърта дъга, които формират ектодермална ниша, наречена цервикален синус на Хис.

$\mathrm{C}$ течение на времето обаче цервикалният синус се стеснява до тесен канал, познат ни като цервикална тръба (ductus cervicalis). Тя впоследствие облитерира. Непълната ѝ облитерация води до развитие на фарингеални кисти, с изключение на кистите, произлизащи от първа хрилна дъга. Хрилна фистула, която свързва повърхността на кожата с лумена на предното черво, може да се образува, ако sinus cervicalis персистира, докато сляпо завършваща киста може да се образува или при персистиращ синус, или при неправилно разделяне на затварящата мембрана. Постепенно хрилните бразди и джобчета облитерират, с изключение на първата хрилна бразда. Части от нея се вдльбват, за да образуват външния слухов проход.

Редица структури се образуват от хрилните бразди (ектодерма), хрилните дъги (мезодерма) и хрилните джобчета (ендодерма). От първото хрилно джобче се образуват евстахиевата тръба, тъпанчевата кухина, клетьчната система на мастоидния израстък и тъпанчевата мембрана. От второто хрилно джобче се образуват небните тонзили и fossa supratonsillaris. От третото джобче се образуват долните паращитовидни жлези, тимусът и fossa piriformis. Четвъртата хрилна торбичка дава началото на горните паращитовидни жлези.

Както вече споменахме, хрилните дъги имат хрущялен скелет, първична мускулна тъкан, нерв и артерия. От първата дъга се образуват: долната челюст, зъбите, чукчето и наковалнята на средното ухо. От втората дъга се развиват тялото и малките рога на хиоидната кост, както и стремето и processus styloideus. Третата и четвъртата дъга са предшественици на ларингеалния скелет. Що се отнася до артериалната компонента на дъгите, външната максиларна артерия се образува от първа хрилна дъга, а от втората - a. stapedis. Третата дъга участва в образуването на проксималната част на a. carotis interna, a. carotis externa и a. carotis communis. Дъгата на аортата се образува от четвъртата хрилна дъга, както и проксималната част на $a$. subclavia dextra. Артерията на шестата дъга може да персистира като ductus arteriosus вляво, а вдясно формира a. pulmonalis.

Нервът от първата дъга е мандибуларната част на n. trigeminus. Той инервира съответните мускули, които произлизат от същата дъга: дъвкателни мускули, предното коремче на $m$. digastricus, $m$. mylohyoideus, $m$. tensor tympani, $m$. tensor veli palatini. От втората дъга се образуват $n$. facialis, задното коремче на $m$. digastricus, $m$. stapedius и мимическите мускули, както и осмият черепномозъчен нерв. От третата дъга се образуват $m$. glossopharyngeus и $m$. constrictor pharyngis superior. $N$. vagus се образува от четвъртата хрилна дъга и инервира ларингеалните мускули, произлизащи от нея. Единадесетият черепномозъчен нерв произлиза от шестата хрилна дъга.

\section{Кисти на първата хрилна цепка}

Тези хрилни аномалии се класифицират допълнително като тип I и тип II. Хрилна аномалия тип I е с ектодермален произход и се счита за дупликация на външния слухов канал, докато аномалиите тип II се смятат за дупликатури на мембранозния външния слухов канал и ушната мида, които съдържат ектодермални елементи (кожа) и мезодермални елементи (хрущял). Като цяло аномалиите от първата хрилна дъга представляват $1-8 \%$ от всички брахиогенни аномалии. При тип I ce проявяват като кисти, синуси или фистули в преаурикуларната зона, свързани с кожата и външния слухов канал. Тези лезии, разположени обикновенно латерално спрямо седми черепномозъчен нерв, могат да бъдат вклинени в тъканите на паротидната жлеза. Аномалиите тип II, от друга стана, са обикновено разположени близо до ьгъла на долната челюст, надолу или назад. Те също са разположени в паротидната жлеза и могат да се разполагат латерално, медиално или между клоновете на лицевия нерв.

Клинично те се проявяват като паротидни тумори, паротит или оторея/оталгия, ако има връзка с външния слухов канал. Лечението е хирургична ексцизия, която зависи от степента на развитие 
на болестта. Предоперативно за улеснение може да се използва контрастно вещество, с което да се проследи ходът на канала, синусът или фистулата. Поради близостта на кистата с канала на паротидната жлеза и лицевия нерв често се налага повърхностна паротидектомия и внимателна дисекция на лицевия нерв. След като лицевият нерв е защитен, кистата или канальт могат да бъдат отстранени близо или до края им във външния слухов канал. Може да се наложи отстраняване на част от кожата и хрущяла над канала с вторично заздравяване.

\section{Кисти на втората хрилна цепка}

Те представляват най-честите хрилни аномалии. И тук липсата на облитерация на цервикалния синус е причина за наличието на персистираща кухина, тапицирана с епител, която може да има и кожна комуникация. Представят се като безболезнени, флуктуиращи маси високо в страничните отдели на шията. Задният сегмент на кистата се разполага в дълбочина до предния ръб на $m$. sternocleidomastoideus. Тъй като в този регион рядко могат да се наблюдават кистозни образувания от друг произход, диагнозата не представлява проблем, обаче в диференциалната диагноза влизат и такива аномалии като аневризми на каротидната артерия и тумори на слюнчени жлези (паротидна или субмандибуларна) (1, 2). Анатомично каналът продължава нагоре, като преминава странично на каротидната артерия, IX и XII черепномозъчни нерви. Към своя край близо до m. constrictor pharyngis medius или в близост до вътрешния си отвор във fossa tonsillaris каналът преминава между вътрешната и външната карототидни артерии. При хирургичното лечение на тези образувания се използва хоризонтална инцизия над кистата, която се продължава по ширината на $m$. sternocleidomastoideus (поне до средата). След това трактьт се проследява до неговия край, където той се отделя и лигира на нивото на m. constrictor pharyngis medius или в областта на тонзиларната ямка. Ако канальт е по-дъльг, може да се наложи допълнителна хоризонтална инцизия по - нагоре (инцизия тип стълба).

\section{Кисти на третата хрилна цепка}

Разпологат се по предния ръб на $m$. sternocleidomastoideus (обикновено вляво). Тези редки аномалии преставляват канал, който преминава отгоре, латерално и отзад спрямо a. carotis interna. Също така се разполагат над ХІІ ЧМН, но под IX ЧМН. След това канальт върви медиално зад a. carotis interna и влиза във фаринкса в облас- тта на пириформения синус, след като пробива тирохиоидната мембрана. Отворът се разполага над вътрешния ларингеален нерв. Хирургичният достьп е подобен на този при кисти на втората хрилна дъга.

Трябва да се отбележи, че аномалиите на третата и четвъртата хрилни дъги са свързани с периодично повтарящи се остри гнойни тироидити в детска възраст. Обикновено се наблюдава полимикробна инфекция с Clostridium, E. coli, Klebsiella и Proteus, налагащи приложението на агресивна антибиотична терапия.

\section{Кисти на четвъртата хрилна цепка}

Както и кистите на третата хрилна цепка, те са изключително редки аномалии. Разполагат се вляво, в долно предната част на $m$. sternocleidomastoideus. Започват от fossa piriformis, вървят надолу по шията, латерално на трахеята и $n$. laryngeus recurrens, като образуват примка около дъгата на аортата. След това продължават нагоре по шията, малко зад a. carotis communis, където пресичат XII ЧМН. След това започва второ спускане и се отваря на повърхността на кожата в долната част на $m$. sternocleidomastoideus. Ако е налице десностранна аномалия на четвъртата хрилна цепка, тя преминава около а. subclavia, преди да се изкачи към шията. Тези лезии са изключително редки и има малко хирургични процедури, които могат да се приложат $(1,2)$.

\section{Ларингоцеле}

Заедно с аномалиите на хрилните дъги и ларингоцелетата се изявяват под формата на латерални шийни образувания. Въпреки че се наблюдават при всички възрастови групи, най-често се срещат при мъжете между 50- и 60-годишна възраст. Етиологията на ларингоцелето е или вродено увеличение на въздушния сак, или придобито - от увеличено интраларингеално налягане (напр. при тромпетисти). Има три вида ларингоцеле: вътрешно, външно и комбинирано. Вътрешното ларингоцеле се разполага изцяло в ларинкса и обикновено изхожда зад и над лъжливите гласни връзки и ариепиглотичните гънки. Изявата на вътрешното ларингоцеле не е под формата на шиен тумор, тъй като се разполага интралуменно.

Външното ларингоцеле се наблюдава като странично издуване в областта на шията, което преминава през отвора на тирохиоидната мембрана, през който преминават n. laryngeus superior и кръвоносни съдове. Комбинираното ларингоцеле включва в себе си белезите на вътрешното и 
външното ларингоцеле. Клинично се представя със следните симптоми: латерален шиен тумор, дисфагия, кашлица, диспнея и понякога чувство за бълбукане поради излизането на насъбралия се въздух в кухината. При физикалното изследване външното и комбинирано ларингоцеле могат да се проявят при повишаване на интраларингеалното налягане и лесно се смаляват при натиск. Първата им проява може да бъде като laryngopyocele, което се проявява като остро цервикално възпаление, настьпващо при вторично инфектиране и изпълване на сака с гной. Освен клиничните данни за потвърждение на диагнозата се използва КТ.

Лечението на симтоматичните вътрешни и външни ларингоцеле е хирургично, обикновено с външен достъп. Преди инцизията е необходимо щателно ендоскопско изследване, за да се изключи карцином, който може да създава клапа в стомахчето. При 2-18\% от пациентите с ларингоцеле е открит карцином. При външно ларингоцеле се прави хоризонтална инцизия на нивото на кистата върху или под нивото на хиодната кост. Дисекцията се осъществява под platysma, като се отстраняват покриващите меки тъкани, докато се открие кистата пред каротидния съдово - нервен сноп $(3,7)$. След това кистата се проследява до тирохиоидната мембрана с внимателно намиране на n.laryngeus superior. Ако няма значителна вьтрешна компонента, кистата може да се лигира, без да се навлиза в ларинкса. При комбинираното ларингоцеле или голямо вътрешно ларингоцеле може да бъде направена латерална тиротомия за пълна ексцизия. След като се разделят или екартират m.thyrohyoideus и m.sternothyroideus, перихондриумът на тироидния хрущял се инцизира по горната граница и се повдига назад. N.laryngeus inferior се идентифицира и се предпазва от нараняване. След измерване на тироидния хрущял се отбелязва точка над средната част и се свьрзва с точка на горната граница на тироидния хрущял, медиално от входа на n.laryngeus superior. Частичната латерална тиротомия се осъществява или с осцилиращ нож, или трион, като се цели предпазване на ларингеалния лумен. След това вътрешното ларингоцеле може да се идентифицира и да се проследи субмукозно до края му, след което да се лигира. При малки изолирани вътрешни ларингоцелета някои автори съобщават за успешна ларингоскопска лазерна ексцизия.

\section{Тератоми и дермоидни кисти}

И тератомите, и дермоидните кисти представляват аномалии на растежа и развитието, които включват плурипотентни ембрионални клетки и се класифицират в четири групи според герминативния слой, от който произлизат, и от степента на тъканно развитие. Според тази класификация се делят на дермоидни кисти, тератоидни кисти, тератоми и епигнати. Дермоидните кисти са изградени от мезодерма и ектодерма и могат да съдържат космени фоликули, мастни и потни жлези. Разполагат се по срединната линия, безболезнени са и обикновено са в субменталната област. Разграничат се от кистите на ductus thyroglossus по това, че нямат езикова протрузия. Въпреки че обикновено се разполагат под m.mylohyoideus, могат да се разположат и над този мускул по предната част на пода на устната кухина, наподобявайки ранула $(4,5,7)$. Лечението е хирургично - ексцизия. Тератоидните кисти са изградени от екто-, ендо- и мезодерма и могат да бъдат постелени от многослоен плосък епител до респираторен епител. Трябва да се отбележи, че герминативните слоеве не са диференцирани, така че тъканите не представляват органи. Тератомите, от друга страна, са изградени от три герминативни слоя както тератоидните кисти, но има диференциация, която позволява идентифицирането на органи при тези лезии. Тератомите се срещат при 1:4000 новородени и показват тенденция да се локализират в гонадите, ретроперитонеалната, медиастиналната и сакрококцигеалната област. В областта на главата и шията обаче тези големи, капсулирани полукистични маси могат необичайно да бъдат открити в назофаринкса, носа, орбитата, устната кухина или шията. Полихидрамнион се наблюдава в 18\% от случаите на шийни тератоми. Тератомите на шията се откриват още при раждането и могат да причинят респираторен дистрес в зависимост от размера си. Трябва да се отбележи, че шийните тератоми могат да бъдат интимно свързани с щитовидната жлеза и могат да предизвикат компресия на трахеята и на хранопровода. Тъй като тези лезии спират притока на въздух, хирургичната ексцизия се осъществява по спешност. Повечето тератоми са доброкачествени, но в 20\% от случаите става въпрос за злокачествено заболяване със съществена вариация в зависимост от мястото на възникване, например по-чести са при тератомите на гонадите, отколкото при тези на шията (рядко) (3). При малигнени лезии след хирургичната ексцизия е необходима химиотерапия или лъчелечение. Епигнатите представляват последната група и имат значителна степен на диференциация с развити фетални органи и крайници. Те най-често са несъвместими с живота. 


\section{Кисти на тимуса}

Срещат се рядко и възникват от остатъци от тимуса, при движението му от долната челюст до срединната линия на шията. Тимусьт се образува от третото фарингеално джобче през шестата седмица от феталния живот и се спуска в гръдния кош до деветата седмица, като запазва връзка с перикардиума. Тъй като долните паращитовидни жлези също се образуват от третото фарингеално джобче, те също могат да бъдат открити интраторакално, ако се спуснат надолу с тимуса. При спускането на тимуса все още има комуникация с третото джобче, която се означава като ductus thymopharygeus, който обикновено облитерира до осма - девета седмица. Ако тази комуникация персистира, може да доведе до развитието на шийни тимусни кисти. Те могат да се разполагат по срединната линия или по предната повърхност на $m . s$ ternocleidomastoideus, като имитират аномалии на хрилните дъги (1). Допълнително могат да останат свързани с тимуса в гръдния кош или с фаринкса чрез епителиален канал през тирохиоидната мембрана. Лечението е хирургична ексцизия.

\section{Кисти на ductus thyroglossus}

Тези кисти могат да се разположат навсякъде по средната линия по хода на феталното спускане на щитовидната жлеза от foramen cecum. На седемнадесетия ден на бременността започва спускането на щитовидния зародиш от foramen cecum, като преминава пред, зад или през хиоидната кост по пътя към крайното си местоположение. От всяка щитовидна тъкан, която остане в тази област, може да се развие киста. Обичайно се представя като тумор в срединната линия, който бързо се увеличава след инфекция на горните дихателни пътища, най-често при деца, но може да се срещне и при възрастни. Тези маси обикновено са с големина между 2 и 4 см и водят до протрузия на езика. Карцином от кисти на ductus thyroglossus се наблюдава рядко - под $1 \%$. При физикалното изследване е необходимо да се палпира за нормална щитовидна тъкан, тъй като кистата може да бъде единствената функционираща щитовидна тъкан при този пациент. Ако не се палпира нормалната щитовидна тъкан или изследването не е задоволително, е необходимо да се направи радиоизотопно изследване на жлезата.

Лечението е хирургично - ексцизия. Локалната ексцизия не е показана поради високия риск от рецидив. Хирургичното лечение включва повдигане на късо повърхносто разположено ламбо малко под нивото на хиоидната кост на нивото на кистата. Дисекцията се осъществява до кистата, за да може кистата да се отстрани допълнително от меките тъкани. Това се прави до корена на езика. Преди да се навлезе в корена на езика, централната част на хиоидната кост се освобождава, като се използва форцепс за срязване на костта. Това ще позволи адекватна ретракция, тъй като кистичният канал се проследява до foramen cecum, където се изрязва заедно с част от корена на езика. Счита се, че отстраняването на част от хиодната кост и корена на езика намалява рецидивите до $3 \%$.

\section{Ранула}

Ранулата е ретенционна киста на подезичната жлеза след възпалително заболяване, която се разполага леко встрани от срединната линия в субменталното пространство. Диференциална диагноза се прави с дермоидна киста (6). Клинично разликата е, че ранулата се разпростира до пода на устната кухина и обикновено встрани от срединната линия. Лечението включва ексцизия на кистата заедно със засегнатата сублингвална жлеза.

\section{Хемангиом}

Това е най-често срещаният тумор в детска възраст. Честотата му е 10-12\% при недоносени и доносени деца и средно 23\% при деца, родени с тегло под 1000 грама. Съотношението жени:мъже е $3: 1$. В $20 \%$ от децата се срещат множествени хемангиоми. Особено важно е, че при повече от $50 \%$ от пациентите с цервикофасциални хемангиоми има и ларинготрахеални лезии. Повечето хемангиоми (повърхностни или дълбоки) се откриват през първите шест седмици след раждането. Повърхностният хемангиом представлява лезия, по-висока от кожната повърхност, с височина от 0,5 до 5 см и ярко червен цвят, докато дълбокият хемангиом е покрит с кожа, която е леко надигната, със синкав отенък. Дълбоките хемангиоми трудно могат да се отдиференцират от лимфангиом. Диагнозата се поставя по клиничната изява, използват се и доплерово изследване на кръвния ток, ЯМР, КТ и/или ангиография, за да се улесни диагностичният процес. Клинично хемангиомите преминават през пролиферативна фаза, през пьрвите 8 - 12 месеца, последвана от инволюция през следващите години. Изследвания показват, че при $50 \%$ от децата настъпва намаляване на лезията на петгодишна възраст и нараства до $70 \%$ при деца на седемгодишна възраст. Освен това има значително подобрение до десет-дванадесетгодишна възраст. Поради самостоятелното намаляване на лезията наблюдение на развитието ѝ със серийни 
снимки може да е единственото, което е необходимо. В някои редки случаи може да се започне лечение - при зрителни нарушения, субглотични лезии, улцерации, хеморагия, застойна сърдечна недостатъчност, мастни промени от хемангиома и тромбоцитна коагулопатия.

При деца с лезии в горната периорбитална област може да се наблюдават значителни зрителни нарушения, които причиняват амблиопия, а промени в корнеята могат да причинят грешки в рефракцията, водещи до астигматична амблиопия. При субглотисни хемангиоми нуждата от лечение е очевидна. Детето може да има бифазен стридор, когато хемангиомът е в пролиферативната си фаза ,или първоначално да се изяви като протрахиран или хроничен ларинготрахеобронхит. Могат да се появят улцерации и кървене при увеличаване размера на хемангиома и инфилтриране на епидермалната базална мембрана. Лечението зависи от сложността и големината на лезията. Едно от най-сериозните усложнения на хемангиома е застойната сърдечна недостатъчност. Сърдечната недостатъчност се появява при големи цервикофациални хемангиоми или при пациенти с кожни и висцерални лезии, най-вече в черния дроб. Тромбоцитната коагулопатия, известна още като синдром на Kasabach-Meritt, се проявява в началото на пролиферативната фаза и клинично се проявява с петехии, екхимози и възможни посериозни хеморагии от храносмилателната, дихателната или централната нервна система (6). При изследване на хематологични показатели типично се открива тежка тромбоцитопения, ниско ниво на фибриногена и много удължено протромбиново и тромбопластиново време. Въпреки лечението смъртността достига 30 - 40\% при пациентите с тромбоцитна коагулопатия. За лезиите, изискващи лечение, вариантите са лекарствена терапия, лазерна аблация и хирургична ексцизия.

Високи дози кортикостероиди (2 до 3мг/кг/дневно) са ефективни при лечение на рискови хемангиоми, като 30-60\% от тях отговарят на лечението. От няколко часа до дни от началото на лечението трябва да настьпи подобрение. Ако не се наблюдава подобрение след 7 дни, се счита, че лезията не може да бъде повлияна. При лезиите, които се повлияват, кортикостероидите се намаляват до по-ниски дози и лечението продължава, докато лезията премине в инволюционен стадий (от 10 до 12 месеца). Освен венозните кортикостероиди ефективно се прилагат и инфилтрации на лезията с триамхинолон ацетат и бетаметазон на всеки 46 седмици. Интерферон алфа 2а също се прилага при лечение на хемангиоми поради антиангиоген- ния си ефект. Предварителните отчети показват обещаващи резултати, особено при пациенти със синдром на Kasabach-Meritt. При деца със субглосални хемангиоми със симптоми на респираторен дистрес и особено при тези, които не се повлияват от системните кортикостероиди може да се използва $\mathrm{CO}_{2}$-лазер за аблация на лезията. Хирургична ексцизия в детска възраст може да се приложи, за да се отстранят фиброадипозни резидуални тъкани или кожна отпуснатост след инволюцията на лезията. Освен това в някои случаи с тежки психосоциални проблеми, особено при деца с носни или устни лезии, субтотални ексцизии с контуриране са показани.

\section{Васкуларни малформации}

Представляват голяма група лезии, която включва капилярни, венозни, лимфни и артериовенозни малформации. За разлика от хемангиомите васкуларната малформация е налична още при раждането и нараства пропорционално с растежа на детето, въпреки че тези лезии могат бързо да нараснат при травма, инфекция и хормонални промени (например пубертет и бременност).

Капилярните малформации съдържат множество дилатирани капиляри или венули, които обикновено се разполагат в повърхностните слоеве на дермата. Важно е да се отбележи, че децата с лезии, които обхващат r.ophthalmicus на n.trigeminus, могат да имат и синдром на Sturge-Weber. При този синдром се наблюдават едновременно капилярни, венозни и артериовенозни малформации на лептоменингите, което води до прогресивна атрофия и дегенерация на мозъчната кора. Лазерната терапия е ефективна и се счита за метод на избор. При възрастни аргоновият лазер предизвиква термична тромбоза на лезията с последващо изсветляване и изглаждане на кожата. Лазер с пулсираща цветна светлина може да бъде полезен при по-малки деца, при пациенти със слабо оцветени лезии и при пациенти със силно чувствителна на термични дразнения кожа. При определени случаи може да се наложи хирургична ексцизия с реконструкция с регионални кожни ламба, автоприсадки или тъканна експанзия.

Венозните малформации се определят като кавернозни хемангиоми или варикозни хемангиоми. Хистологично тези лезии се характеризират със силно дилатирани или ектатични васкуларни канали, покрити с нормален ендотел и често асоциирани зони на тромбоза. Могат да се наблюдават също капилярни или лимфни аномалии във венозните малформации. Тези лезии обикновено 
се наблюдават в областта на устните или бузите и са меки, поддаващи на натиск, непулсиращи и бързо се изпълват с кръв след отпускане. Описани са венозни малформации, разположени в скелетната мускулатура - особенно в m.masseter, както и в краниофациалния скелет, например мандибулата. Рентгенологично патогномоничен белег за интраосалните лезии е видът на „пчелна пита“ или „сапунени мехури““ $(6,7)$. Поради бавния ток на кръвта тези лезии са склонни към флеботромбози, които се манифестират с болезненост и чувствителност. При лечението на големи или симптоматични венозни малформации е показана хирургична резекция, често субтотална, което води до отстраняване на голямо количество тъкани и подобряване на контурите, докато инжектирането на склеротичен агент в центъра на лезията е подходящо при по-малки селектирани лезии. При склерозирането трябва да настыпи оклузия на навлизащите артериални и излизащите венозни съдове.

Лимфните малформации се характеризират с множество дилатирани лимфни канали, които могат да съдържат компоненти на капилярните аномалии (лимфно-капилярна малформация) или венозни аномалии (лимфно-венозна малформация). Често се наблюдава значителна хеморагия в лимфните пространства. Има голямо разнообразие при тези лезии. Те варират от кистичен тип (описват се като кистичен хигром), който се появява предимно в задния шиен триъгълник и е с по-малка инфилтрация в околните тькани до по-тежьк вид с екстензивна инфилтрация в околните тькани. Някои лимфни малформации могат да се свържат с костна или мекотъканна хипертрофия. Създадена е и официална класификация на лимфните малформации. Тип 1 са лезии под m.mylohyoideus и обичайно се разполагат в предния и задния триъгълник. Тези лезии са добре отграничени, кистични и дискретни, без следа от инфилтрация на околните структури, както беше отбелязано за кистичните хигроми.

За разлика от тях тип 2 малформации се разполагат над m.mylohyoideus и се наблюдават предимно в устната кухина, устните и езика. Тези лезии имат по-силна клинична изява, с неясни граници до инфилтрацията в съседните структури. Лечението е хирургична ексцизия, която е с по-добър резултат при тип 1 лезии, отколкото при тип 2. При лезии тип 1 тоталната резекция обикновено е възможна и може да се осьществи през пьрвите 9-12 месеца след раждането. При лезии тип 2 очакванията са за многократни процедури и е малко вероятна тоталната резекция. Когато отстраняването на лезията не е безопасно, например супраглотис, подходящо е прилагането на $\mathrm{CO}_{2}$ лазер.
Добре кръвоснабдените васкуларни аномалии на главата и шията се характеризират с артериовенозни малформации. При хистологично изследване се наблюдават множествени артериовенозни шънтове на артериални съдове с упльтнени стени и различен размер с венозни съдове със съпьтстващи промени: хипертрофия, задебеляване на интимата и вторична склероза вследствие на високия дебит, причинен от шънтовете. Клинично тези лезии са еритематозни макули по кожата с пулсации при палпация и аускултаторен щум. Тези лезии, като повечето васкуларни малформации, могат да се променят внезапно при травма, инфекция или хормонални промени. Клинично тези лезии могат да причинят кожна некроза и вторична краниофациална деструкция при шънтиране на кръвта от тези структури, както и компресивни и ерозивни ефекти. Поради доброто крьвоснабдяване на тези лезии сърдечната недостатъчност може да бъде съпътстващо заболяване. При симптоматични лезии се налага предоперативна оценка на лезията с ЯМР, както и ангиография, която позволява да се направи суперселективна емболизация на лезията, ако това е индицирано. Дьлгосрочният успех обаче изисква тотална резекция на засегнатите тъкани често със сложна реконструкция - присаждане на микроваскулавизирана тъкан.

\section{Дупликатури на хранопровода}

Дупликатурите на хранопровода, макар и редки, могат да се проявят като образувание по срединната линия на шията. Счита се, че се получават при смутена реканализация, настъпваща след солидната фаза от ембрионалното развитие, с образуване на кисти от абнормни остатъци от предното черво. Кистата може да бъде постлана със сквамозен, респираторен, чревен или смесен със секреторен епител, което води до постепенно увеличение на кистата. Стомашните сокове, които се отделят от лигавицата (често срещано при тези структури), могат да доведат до сериозни усложнения, ако възникнат улцерации и хеморагия. Повечето от тези лезии протичат безсимптомно, докато не се открият случайно на рентгенография на гръден кош. При симптоматичните лезии оплакванията на пациентите са по-често респираторни, отколкото трудности при прегльщане или наличие на шийна подутина. Доминиращите симптоми са стридор, рецидивиращи пневмонии или кашлица. При новородени може да се прояви с чист респираторен дистрес вследствие на обструкцията. При редките пациенти шийното образувание е типично разположено по срединната линия и може да достигне 
огромни размери в зависимост от активността на секреторната лигавица. При пациенти с каквато и да е аномалия на горния гастроинтестинален тракт трябва да се мисли и за други вродени аномалии, особено вертебрални. Например миелоцеле може да се появи заедно с дупликационна киста на хранопровода, докато рядко също така може да има комуникация между кистата и гръбначния стълб. При оценката на тези лезии КТ е безценна с флуороскопски или обикновен филм също допринася за диагнозата и плана за лечение. В литературата се отбелязва, че ендоскопското изследване и използването на бариев сулфат са недостатъчно ефективни при диагнозата и предоперативното планиране на кистите на хранопровода. Ендоскопски субмукозно образувание с нормална мукоза е типична находка, което я прави трудна за отдиференциране от други лезии като лейомиома. Същото се отнася и за бариевия сулфат. Въпреки че е с по-трудно техническо изпълнение, ендосонографията се използва, за да подпомогне диагнозата. За лезиите, които комуникират с гръбначния канал, се налага миелография. Лечението е хирургична ексцизия. Според разположението на кистата подходът може да бъде шиен, торакотомия или лапаротомия за пълно отстраняване на формацията. При невроентерична комуникация се налага внимателна дисекция и затваряне.

\section{Коментар}

Дупликационните кисти на хранопровода се считат за аномалии на горния гастроинтестинален тракт. Могат да бъдат предни, които засягат трахеята; задни - засягат гръбначния канал, или по срединната линия със засягане на хранопровода. Могат да имат обща стена с хранопровода и рядко комуникират с неговия лумен. За да се определи локализацията на кистата, нейните стени и т.н. се използват ултразвук, КТ и ЯМР. Подходяща е ексцизия с латерален шиен достьп.

Тъй като хемангиомите имат тенденция да инволюират, консервативното лечение е препоръчително освен в случаите, когато има функционално нарушение на зрението, въздухоносните пътища, прегльщането или инервация. При тези случаи могат да се използват стероидни препарати, но трябва да се имат предвид страничните ефекти от тази терапия, включително високо кръвно налягане, повишено вътречерепно налягане и контакт с болни от варицела. Вродените лимфни малформации нямат тенденция да инволюират и трябва да бъдат отстранени с щадене на виталните структури, когато детето е на подходяща за операцията възраст и преди реинфекция, която да направи операцията по-трудна.

\section{Литература:}

1. Bailey, Byron J, ed. Head and Neck Surgery Otolaryngology. J.B. Lippincott. Philadelphia. 1993.

2. Benjamin, Bruce. Diagnostic Laryngology. W.B. Saunders Company. 1990.

3. Bhutani, MS, Hoffman BJ, and Reed C. Endosonographic Diagnosis of an Esophageal Duplication Cyst. Endoscopy. (28): 396-297, 1996.

4. Bluestone, Charles D and Stool, Sylvan E., eds. Pediatric Otolaryngology. Second Edition. W.B. Saunders Company. 1990.

5. Crussi-Gonzalez, F. Extragonadal Teratomas. Armed Forces Institute of Pathology. 1980.

6. Cummings, Charles W, ed. Otolaryngology - Head and Neck Surgery. Second Edition. Mosby Year Book. 1993.

7. Tucker, Harvey M. The Larynx. Second Edition. Thieme Medical Publications. 1993.

8. Whitaker, JA, Deffenbaugh LD, Cooke AR. Esophageal Duplication Cyst. Case Report. American Journal of Gastroenterology. 73 (4) : 329332. 1980.

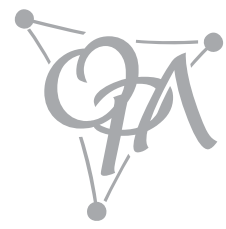

